\title{
Implementing the IA stage and developing an instrument to assess the fidelity of critical time interventional: task shifting
}

Implementação do estágio IA e desenvolvimento do instrumento de avaliação da fidelidade da intervenção para períodos críticos: transferência de cuidados

Tatiana Fernandes Carpinteiro Silva

Resumo da Tese de Doutorado apresentada ao Instituto de Estudos em Saúde Coletiva da Universidade Federal do Rio de Janeiro. Área de Epidemiologia em Saúde Mental. Rio de Janeiro RJ, Brasil.

Correspondence: Tatiana Fernandes Carpinteiro Silva; Avenida Horácio Macedo, s/n, Itha do Fundão, Cidade Universitária, Praça Jorge Machado Moreira; 21944-970 Rio de Janeiro RJ, Brasil; E-mail: tatiana_fcs@hotmail.com

Orientador: Giovanni Lovisi.

Received 26 May 2014; Received in final form 11 June 2014; Accepted 1 July 2014.

\section{ABSTRACT}

One strategy that has been used for treat patients with mental health disorder is the implementation of psychosocial interventions. Like the development of a new drug, which requires safety studies before efficacy assessment, the psychosocial interventions should be implemented following defined stages, with the objective of increase the validity and reliability of such interventions. These stages are IA (pre-pilot), IB (pilot study), II (randomized clinical trial) and III (additional studies). This study proposes a description of all activities carried out in implementation of the pre-pilot (IA) Critical Time Intervention - Task Shifting (CTI-TS), including the development of manuals and the development of an instrument to assess fidelity to the original protocol. As a result, were performed the adaptation of instruments to be used in the pilot study, the adaptation of CTI-TS manual to Brazilian context, the adaptation of the agents CTI-TS training manual, as well the development of the CTI-TS assessment scale fidelity and its instruction manual. This allows multicentric studies conducted in different contexts could be performed avoiding biases. Considering that Brazil is a country that lacks resources allocated to mental care, it is expected that more psychosocial interventions can be implemented, since it was possible to develop the implementation process according to the methods recommended by the international scientific literature.

Keywords: intervention studies, guideline adherence (fidelity), health plan implementation. 